\title{
Una aproximación teórica a la crítica enológica como subgénero periodístico de opinión
}

\section{José Ignacio Armentia Vizuete}

Catedrático de Periodismo. Universidad del País Vasco.

\section{José María Caminos Marcel}

Catedrático de Periodismo. Universidad del País Vasco.

\section{Flora Marín Murillo}

Profesora titular de Comunicación Audiovisual. Universidad del País Vasco.

Resumen:

La crítica periodística, desde sus mismos orígenes, ha estado estrechamente vinculada al consumo de obras artísticas, literarias o culturales en general. En los últimos años, con la consolidación del denominado "periodismo de servicios", el objeto de la crítica se ha ampliado hacia bienes de consumo masivo. En el contexto de este tipo de textos de opinión, cuya función es la de asesorar al consumidor, es en el que se produce la aparición de la crítica enológica, una variante periodística que comienza a contar con características propias y diferenciadoras. En este artículo se pretende ofrecer una aproximación teórica a la crítica enológica como subgénero del periodismo de opinión.

Palabras clave:

Crítica enológica - Crítica de vino - Géneros de opinión

\section{Abstract:}

The journalistic criticism, from his origins, has been narrowly joined to the consumption of literary, cultural or artistic works, in general. In the last years, with the consolidation of the called "journalism of services", the object of the criticism has been extended towards products of massive consumption. The apparition of the criticism of wines has happened in the context of these opinion texts, whose function is that of assessing the consumer. The criticism of wines begins to have own characteristics. The objective of this article is to offer a theoretical approach to the criticism of wines as an opinion subgenre. 
Key words:

Criticism of wines - Enological criticism - Opinion genres.

\section{La crítica y los géneros periodísticos}

Para analizar la crítica de vinos debemos partir inicialmente de lo que consideramos que son las características esenciales del género periodístico conocido con el nombre de crítica. Lo hacemos así porque, posteriormente, pretendemos observar si la crítica de vinos cumple con los requisitos genéricos propios de la crítica periodística.

Como punto de partida podemos decir que existen algunas discrepancias a la hora de encuadrar la crítica periodística dentro del campo de los géneros periodísticos. Así, aunque se trata de un punto de vista que no es común a otros autores, Núñez Ladevéze (1995: 109) afirma que la crítica es "una modalidad de crónica temática sobre un acontecimiento político, cultural o deportivo”. Para este autor, al tratarse la crítica de una modalidad de crónica, encuadra este género periodístico dentro del campo de los géneros interpretativos, o como él mismo prefiere denominarlos, "géneros complementarios de la noticia de actualidad".

Los géneros periodísticos interpretativos son más analíticos. El periodista profundiza sobre un acontecimiento, que casi siempre forma parte del diario acontecer, y se introduce en él mediante el análisis de los hechos que lo circundan y las argumentaciones que refuerzan los postulados que defiende el periodista.

Nosotros creemos que una buena crítica periodística, que se sustenta también en el análisis, debe ir más allá de la interpretación, debe contener valoraciones. Es decir, juicios categóricos que orienten al lector sobre las cualidades de los productos criticados.

Por eso, casi todos los autores prefieren enmarcar la crítica dentro de los géneros de opinión. Es decir, dentro de toda esa gama de formas de expresión y comunicación que buscan convencer al lector sobre los puntos de vista que mantiene el periodista. Unos géneros basados en la persuasión y en los que la información sobre el acontecimiento del que se opina tiene un interés complementario, a pesar de que la información está presente en la crítica.

Es, quizás, el escaso interés que muestran los géneros opinativos sobre la información estricta, lo que agrega complejidades a la hora de encuadrar la crítica dentro del campo de los géneros periodísticos. Y esto es así porque, a diferencia de sus géneros de opinión hermanos, la crítica sí suministra información. En la crítica periodística encontramos información y opinión, pero si lo encuadramos en el campo de los géneros de opinión es porque la información desempeña siempre una función complementaria y muy secundaria sobre las opiniones que se reflejan. 
Estas dificultades para encuadrar la crítica dentro de un campo específico de los géneros periodísticos es muy normal si tenemos en cuenta que la creatividad periodística ha conducido a lo largo de las últimas décadas a la aparición de multitud de géneros híbridos que son muy difíciles de ubicar en una clasificación cerrada.

Como la crítica periodística informa, interpreta y juzga, arrastra tras de sí cualidades que hacen que sobre el papel pueda enmarcarse tanto dentro de los géneros interpretativos como en los de opinión. De ahí que haya autores como Núñez Ladevéze que la ubiquen en el campo de los géneros interpretativos, y más concretamente dentro de la crónica temática.

Mary Luz Vallejo (1994: 60) también habla de las dificultades para ubicar la crítica dentro del campo de los géneros periodísticos. "El género crítico -afirma- se puede asimilar a la columna de opinión que orienta, analiza, valora y enjuicia. Algunos autores la distinguen como columna de ensayo o columna personal, a medio camino entre la literatura y el periodismo, y firmada por reconocidos escritores".

A pesar de estas discrepancias de partida existentes entre unos u otros autores, vamos a considerar la crítica como un género estrictamente de opinión, fundamentalmente porque se sustenta en un aspecto clave de este tipo de géneros: el convencimiento del lector sobre la base argumental que presenta el autor.

Por eso podemos decir que cuando hablamos de la crítica periodística, como podremos comprobar en las líneas siguientes, estamos ante un género de opinión singular, que se sale de los patrones más herméticos de los otros géneros de opinión.

La crítica periodística ha estado históricamente vinculada al juicio de expertos, periodistas o no, sobre el trabajo de terceras personas, fundamentalmente relacionadas con las obras literarias y científicas, la música o las artes plásticas.

La mayoría los autores, al hablar de la crítica, hacen hincapié en la valoración que un experto ejerce sobre "las novedades o las reposiciones de obras de creación, dentro del ámbito de las Artes Plásticas, del Cine, del Teatro, de la Música, del Ballet, que se muestran al público" (Armañanzas y Díaz Noci, 1996: 135).

Este mismo enfoque de la crítica periodística lo encontramos en casi todos los autores que se refieren a este género periodístico. Sin embargo, consideramos oportuno destacar aquí la gran relevancia adquirida especialmente a lo largo de los últimos años por la crítica periodística ejercida no sobre los ámbitos de la creación literaria o plástica, sino directamente sobre bienes dedicados al consumo del público.

\section{La crítica periodística y el consumo}

La crítica periodística, desde sus mismos orígenes, ha estado estrechamente vinculada al consumo. Otra cosa diferente es que hasta ahora no se haya observado la crítica periodística desde la vertiente de su 
conexión con el consumo de masas. Es cierto que su objetivo fundamental no ha sido el de impulsar el consumo de una obra artística o literaria. Sin embargo, desde el mismo instante en que una crítica puede hacer vender directamente una obra, o llenar de público un cine o un teatro, o, más recientemente, impulsar el consumo de determinados bienes entre las audiencias, no podemos desvincular este género periodístico del consumo de los lectores.

Los mismos autores clásicos ya apuntaban algunos retazos de este enfoque que aquí defendemos y vinculan la crítica periodística con una vertiente claramente consumista encaminada a la venta directa o indirecta del producto que se critica.

Así, Emil Dovifat, un clásico alemán en los estudios de Periodística, es el primer autor que destaca la importancia que tiene la crítica para influir en la aceptación o rechazo de los productos que se critican y vincula este género al desarrollo de las sociedades de consumo. Por eso, haciendo extensivas sus reflexiones, cuando las expresiones artísticas se convierten en productos masificados, cuando se populariza la cultura y las expresiones artísticas, surge la crítica periodística como un instrumento imposible de desvincularlo del consumo de masas.

Para este autor (1960: 61), “en el momento en que el arte abandonó el ámbito sacro, en cuanto tuvo que procurarse los medios para vivir y crear en público y para ello ofreció su producto a cambio de un pago, la crítica del público había comenzado. Y encontró su expresión en el periódico”. Es decir, no podemos concebir el desarrollo popular y masivo del arte sin vincularlo a expresiones periodísticas que lo observan y analizan críticamente. Desde los primeros instantes de la actividad periodística, la popularización y masificación de las expresiones artísticas, el paso del arte sacro a las expresiones artísticas de masas, no son ajenas a los medios de comunicación ni a las críticas periodísticas.

Por eso, el desarrollo de la crítica periodística viene de la mano de la cultura de masas. En el marco de estas coordenadas, la crítica no sólo evalúa las obras de los artistas, sean del ámbito que sean, sino que, al mismo tiempo, marcan pautas necesarias para el consumo. De ahí que las reflexiones de Emil Dovifat tengan un especial significado cuando afirma que solamente cuando la crítica "salió del atrio de la iglesia y entró en el campo del entretenimiento popular y luego en la esfera del interés ciudadano y artístico, la crítica individual se hizo pública y se cobró por ella”. Es decir, la creación artística siempre ha estado vinculada a la crítica, pero cuando la existencia de los medios de comunicación permite el ejercicio de la crítica periodística masiva es cuando también las expresiones artísticas se masifican. Masificación artística y desarrollo masivo de los medios de comunicación han ido directa o indirectamente de la mano.

Desde otro punto de vista podemos decir que, es tal la incidencia que puede tener una crítica en el consumo que, como veremos posteriormente, la mayoría de los autores destacan la honestidad del periodista que la practica como una de las cualidades imprescindibles para trabajar con este género periodístico. 
Esta vinculación de la crítica con el consumo la encontramos también en otros autores. Así, Esteban Morán Torres (1988: 24) afirma que "el crítico se encuentra así en situación privilegiada para promocionar ideas, espectáculos, obras de arte, etc. Y también a las personas: autores, artistas, deportistas, etc. Los artículos del crítico pueden servir a unos de trampolín hacia la fama y a otros de guillotina. Porque, para bien o para mal, la crítica ejercida en los grandes medios se convierte, muchas veces, en un eficaz instrumento publicitario".

Juan Gutiérrez Palacio (1984: 282), cita a Brooks Atkinson (Times, de Nueva York) para referirse a la importancia de la crítica periodística en el consumo del producto que se critica. "A veces -se refiere a los críticos- son denostados por su miopía artística, pero por lo general se les acusa de arruinar el capital invertido por un productor, de perjudicar los bienes de un negocio y de arrojar a los actores de sus empleos. [...] es casi imposible que una obra tenga éxito cuando los críticos expresan unánimes una opinión desfavorable. [...] Hasta este extremo el crítico está, y no por su culpa, relacionado con el negocio teatral".

Este mismo autor (1984: 283) cita a González Ruiz, autor clásico de la periodística española, para referirse a este mismo punto de vista. Según González Ruiz, la suerte inmediata de una obra entre el público depende en mucho de lo que el crítico diga.

La crítica periodística busca movilizar urgentemente al público y, precisamente, su importancia deriva de esa posibilidad. En la actualidad, dentro del imparable desarrollo que tiene lo que hemos denominado Periodismo de Servicios, se ha iniciado el despegue de una variedad ilimitada de críticas periodísticas dedicadas a potenciar el consumo de determinados bienes mediante el convencimiento directo del lector.

Consideramos necesario incluir este enfoque de la crítica periodística estrechamente vinculada al consumo porque muchas de las cualidades que históricamente se han vinculado a este género periodístico necesitan ser revisadas desde esta perspectiva.

Por eso, también decimos que la crítica periodística es, dentro de los géneros periodísticos que buscan la persuasión del lector, un género singular. Coincide con el resto de los géneros de opinión en que se sustenta en la argumentación persuasiva para convencer al lector, para modificar o reforzar los sistemas de valores y las actitudes. Pero al contrario de lo que sucede con otros géneros de opinión, que buscan o pueden buscar efectos en las audiencias a medio o largo plazo, la crítica periodística está marcada por la urgencia. Una buena crítica debe movilizar inmediatamente al lector, convencerle rápidamente, porque esa es su esencia y eso es precisamente lo que busca el lector: que le resuelvan las dudas que pueda tener, que le orienten sobre la validez o no de determinadas obras o productos para poder decidir casi instantáneamente si debe consumirlos o no.

Así, desde estas reflexiones, también podemos referirnos a los claros puntos de conexión que tiene la crítica periodística con la propaganda. La crítica periodística tiene unos claros componentes propa- 
gandísticos e incluso una vertiente publicitaria que busca resolver dudas inmediatas para inducir al consumo del lector. Este punto de vista es compartido por Juan Gutiérrez Palacio (1984: 219) cuando afirma que "resulta difícil desligar la crítica de la propaganda. En muchos casos, las críticas irresponsables que abundan en elogios por mercantilismo o servilismo, son auténticos trabajos propagandísticos".

Si bien resulta en ocasiones complicado deslindar el campo de la crítica periodística con las técnicas estrictamente propagandísticas o publicitarias, es lícito decir, como afirma Mary Luz Vallejo (1994: 40) que "cuando la argumentación se inspira en razones publicitarias o ideológicas, recurre a estrategias ilícitas de persuasión que pasan por el uso del lenguaje subliminal, por generalizaciones irreflexivas, por distorsión de las ideas y confusiones terminológicas”.

\subsection{La reseña periodística}

Para ir delimitando claramente lo que entendemos por crítica periodística, consideramos oportuno dejar constancia de las diferencias que existen entre la crítica y la reseña periodística. Históricamente se ha tendido a identificar a los críticos con los periodistas autores de reseñas periodísticas. De hecho, hay autores que se refieren a la crítica periodística utilizando como sinónimos: reseña, glosa, artículo crítico, etc. A pesar de estas identificaciones, la reseña y la crítica periodística tienen más diferencias de las que a simple vista pudieran aparentar.

Así, hay autores que vinculan la reseña con los textos eminentemente informativos, mientras que consideran las críticas como textos interpretativos u opinativos. Así, Mary Luz Vallejo describe la reseña como un texto informativo y, a pesar de ello, no duda en presentarla como una variante de la crítica, a la que considera claramente opinativa. Esta autora habla de la crítica en los siguientes términos: "Habría que catalogar como subgénero la simple reseña informativa o gacetilla, variante noticiosa de la crítica, que se agota en la breve descripción de la obra, la mayoría de las veces copiada de la información de solapa, con una mínima extensión (150 palabras por promedio), y generalmente sin firma" (1993: 38).

En correspondencia con sus argumentaciones, para Mary Luz Vallejo es importante diferenciar entre crítico y reseñador, y considera que los reseñadores son periodistas que elaboran breves textos de urgencia sobre algún acontecimiento, pero que eluden expresar sus opiniones y se limitan exclusivamente a informar.

Al igual que Mary Luz Vallejo, Luisa Santamaría es partidaria de considerar a la reseña como un texto eminentemente informativo. Así, para esta autora, "el comportamiento periodístico frente al arte y las letras tiene algunas variantes que no deben confundirse con la crítica propiamente dicha. Una de esas variantes es la informativa, a la que se denomina profesionalmente reseña periodística de arte: es una noticia sobre un acontecimiento artístico cultural (concierto, exposición pictórica, presentación de 
un libro, representación teatral, etc.) donde el periodista trata al material acumulado de la misma manera como lo hace con cualquier otro conjunto de datos noticiables, de modo objetivo, lo más objetivo posible. Por tanto, la reseña tiene por objeto, básicamente, informar" (1997: 146).

Esta consideración que hace esta autora de la reseña como un texto eminentemente informativo le obliga posteriormente, en consecuencia, a realizar una diferencia clara entre reseña y crítica desde el punto de vista de su ubicación en el campo de los géneros periodísticos. De ahí que, tras sus argumentaciones añada que "como es sabido, la reseña pertenece al estilo informativo y la crítica al de solicitación de opinión” (1997: 147).

Hay otros autores, sin embargo, que consideran la reseña como una crítica breve. Es decir, un texto opinativo más ligero y urgente que la crítica periodística, a la que consideran mucho más densa y reflexiva.

Por eso, también en consonancia con este punto de vista, para estos autores no existen claras diferencias entre un crítico y un reseñador, sino que consideran que ambos realizan funciones similares, aunque distintos papeles. El crítico es un especialista, conocedor profundo del tema sobre el que opina. El reseñador, en cambio, suele ser un periodista que no tiene por qué ser experto en el tema que trata, de ahí que sus textos no tengan que ser tan rigurosos y profundos como las críticas.

Juan Gutiérrez Palacios (1984: 244) es partidario de este punto de vista sobre la reseña periodística y se refiere a ella de la manera siguiente: "La reseña, recensión o reviewing, cuando no es mera bibliografía titular, cuando alcanza lo analítico y acierta a delinear en cuatro trazos los rasgos propios de un autor o una obra, sin perder su provisionalidad, puede ser calificada -ésta sí- de ancilar o crítica de urgencia. De hecho, en nuestros días, ha venido a ser la única expresión crítica de muchas publicaciones".

Después de este ligero recorrido por algunos autores y desde el punto de vista estricto de los géneros periodísticos, la reseña es un texto que añade todo tipo de complejidades, ya que es difícil encuadrarla dentro de un campo específico. Esto es así porque existen reseñas eminentemente informativas, que forman parte de lo que entendemos como géneros informativos, y existen reseñas interpretativas y valorativas, que nos obligan a encuadrarlas dentro de los géneros más estrictamente de opinión.

Si acudimos al Diccionario de la Real Academia de la Lengua nos encontramos con unas referencias a las reseñas en los términos siguientes: "Narración sucinta", por un lado; y, por otro, "noticia y examen de una obra literaria o científica".

La reseña es, en primer lugar, una narración sucinta, es decir, compendiosa, breve. Una narración ligera, más superficial, menos profunda. Aquí encontramos una primera diferencia con la crítica periodística. La crítica es un análisis mucho más profundo y complejo. 
La reseña es, en segundo lugar, "noticia y examen de una obra literaria o científica". Aquí, en esta breve definición, encontramos otra de las claves de lo que es una reseña: noticia y examen. Es decir, información y análisis. Información para describir lo noticioso y análisis para examinar ese hecho noticioso desde unas claves no eminentemente informativas.

Por eso, pensamos nosotros, que la reseña no tiene por qué ser exclusivamente informativa. Tampoco, como opinan otros autores, una crítica de urgencia y, por lo tanto, un texto breve pero claramente opinativo.

La reseña, tal y como la entendemos, es un texto de urgencia que en ocasiones puede ser estrictamente informativo. En otras, puede serlo eminentemente valorativo. Aunque, consideramos que las reseñas más normales son las que incorporan estos dos elementos: la información con la valoración. La reseña, a pesar de su brevedad, interrelaciona los análisis con la información componiendo un todo más superficial que la crítica, pero en el que se entremezcla la información con los comentarios del autor.

Un texto más superficial, menos analítico, no menos experto, que desde el campo de los géneros podemos encuadrarlo perfectamente como un subgénero de la crítica periodística.

De hecho, las reseñas dedicadas a los productos de consumo reúnen casi permanentemente estas dos cualidades que estamos aquí describiendo: la combinación de lo informativo con lo analítico y valorativo. En ocasiones tiene un mayor predominio informativo. En otras, domina lo analítico frente a lo descriptivo. Pero, casi siempre, una buena reseña, aunque sea breve, combina estos dos elementos básicos de los textos periodísticos.

\subsection{La crítica erudita}

Al margen de los parámetros genéricos que aquí estamos desarrollado, pero desempeñando también una función esencial dentro de lo que entendemos por crítica periodística, nos encontramos con lo que podemos denominar crítica erudita, denominada así porque hace juicios extremadamente expertos y normalmente en medios de comunicación que no son necesariamente masivos.

Se trata de una crítica que aparece en las revistas especializadas y normalmente alejada de los parámetros básicos de la crítica cotidiana. Tiene un carácter marginal, porque no llega a públicos masivos. Eso la convierte en una crítica más erudita y especializada, y el periodista o crítico se permite licencias que no tienen cabida en la crítica masiva.

Utiliza un lenguaje mucho más técnico, especializado y dirigido a expertos, ya que en ocasiones puede ser ininteligible para el gran público. Esa erudición de la que hace gala implica que los textos no sean necesariamente argumentativos, ni estén orientados a justificar las apreciaciones del crítico. Se trata de textos categóricos que expresan puntos de vista incuestionables porque están manejados por un gran experto. 
Los suplementos de los medios de comunicación y las revistas especializadas son los lugares habituales para este tipo de crítica que desde el campo de los géneros periodísticos podríamos considerar como un subgénero de la crítica.

Cuando la crítica erudita es breve y sigue los parámetros de la reseña valorativa, a la que ya nos hemos referido, nos encontramos con lo que podemos denominar reseña erudita, que es lo que exactamente practican algunos críticos de vinos.

\section{Importancia de la crítica}

La crítica es uno de los géneros periodísticos más importantes, y también podemos decir que más controvertido. Podemos definir la crítica como el juicio que un periodista experto, o, simplemente un experto en una materia aunque no sea periodista, hace sobre la obra de un autor, sea ésta gráfica, literaria, artística, o del tipo que sea. Por eso es un género tan controvertido, porque su esencia reside en el juicio hacia una obra ajena.

También es controvertido porque asistimos a una forma de expresión y comunicación que recoge con plenitud los aspectos esenciales del trabajo periodístico: la información sobre un acontecimiento, la educación del lector para que pueda profundizar sobre la esencia de ese acontecimiento y la persuasión o búsqueda del convencimiento del público para que haga suyos los puntos de vista que defiende el crítico. Es decir, tres apartados que son básicos en la concepción clásica del periodismo: informar, orientar y educar. Por eso consideramos que la crítica periodística es uno de los géneros más significativos para la persuasión.

A la hora de jerarquizar la importancia de estos tres apartados dentro de la crítica periodística, la mayoría de los autores coinciden en destacar que la crítica incide fundamentalmente en la educación de los lectores.

Así, Luisa Santamaría (1997: 141) explica que "de los mensajes periodísticos, el que más aproximación tiene con la educación es probablemente el de la crítica. Ambos son transmisores de experiencias y de cultura. La crítica examina los fundamentos de nuestras convicciones y creencias, a la vez que elimina ciertas incertidumbres, orienta y reorienta nuestros conceptos sobre la verdad, bondad y belleza de las cosas". En este papel formativo y orientador, el medio de comunicación, a través de un género tan singular, se convierte en un instrumento básico para la educación de los lectores.

Referencias indirectas al papel educador de la crítica las encontramos también en autores clásicos como Emil Dovifat (1960: 66) cuando afirma que "la crítica de arte es un juicio al cual está obligado el crítico subjetivo, pero artística y materialmente responsable, de la obra de arte. Aconseja a los artistas, comunica su obra al público, decanta los valores y los no valores en forma concluyente y con todo ello contribuye al progreso del arte". 
Todas estas observaciones, aún dirigidas a la crítica literaria o a las artes plásticas o escénicas, es necesario matizarlas, sobre todo, si analizamos la crítica especializada orientada más directamente hacia los bienes de consumo.

Así, Juan Gutiérrez Palacio (1984: 219) afirma que "se debe tener en cuenta que la crítica periodística pretende orientar al lector principalmente y, accesoriamente, servirle de fuente de conocimiento erudito. Tarea difícil para la crítica, si se considera la situación del lector promedio de donde se parte para la codificación del mensaje".

Por eso insistimos en que determinado tipo de críticas periodísticas no buscan fundamentalmente la educación de los lectores, sino que, por su propia esencia, hacen hincapié en la persuasión y en la orientación del lector. La crítica de consumo es fundamentalmente persuasiva y busca influir sobre el consumo de las audiencias.

La crítica periodística nace como un género persuasivo dedicado a la crítica de las obras que podríamos enmarcar en el concepto de las Bellas Artes. Sin embargo, tal y como hemos expuesto, aún en su vertiente más cultural tiene una estrecha vinculación con el consumo.

En los últimos años, y de la mano del desarrollo de lo que se ha denominado periodismo de servicios, la crítica ha experimentado un impresionante auge y nos encontramos con críticas periodísticas que abarcan amplísimos campos que se alejan de su motivo primigenio y que se relacionan directamente con el consumo de las audiencias.

La crítica gastronómica, informática, de vehículos, etc. aparecen cada vez con mayor insistencia en las páginas de los medios de comunicación y han abierto nuevos campos a la crítica periodística. Dentro de este marco de interés creciente por las críticas periodísticas relacionadas con el consumo inmediato es donde ubicamos la importancia creciente de la crítica de vinos. En la actualidad, toda la prensa de calidad dedica casi semanalmente apartados a la crítica de vinos, dado el creciente interés de las audiencias por un campo tan complicado y difícil como el que se plantea.

\section{El estilo de la crítica}

No es sencillo establecer unas pautas mínimas sobre las características básicas que debe contemplar una crítica periodística, ni el tipo de razonamientos que se deben utilizar para llevarla a efecto. No es sencillo fijar unos mínimos puntos de encuentro porque los tipos de críticas son amplísimos, tanto como las temáticas que pueden abordar.

En cualquier caso, si tuviéramos que establecer unas pautas comunes para las distintas variedades de este género periodístico podríamos decir que la crítica publicada en los medios de comunicación masivos, en cuanto que va dirigida a públicos muy heterogéneos y con conocimientos dispares sobre 
las temáticas que se juzgan, debe reunir una serie de características específicas entre las que podemos destacar la brevedad, la urgencia y la inteligibilidad. Según Luisa Santamaría (1990: 145) "la crítica periodística debe ser breve, pero no ligera; rápida, pero no irreflexiva; ágil, pero no inconsistente. Y en todo caso será de fácil inteligencia, ya que la mayoría de los lectores carece de formación especializada".

La singularidad de este género persuasivo, que busca el convencimiento urgente, es la que obliga también a utilizar un determinado lenguaje marcado por las tres pautas que anteriormente hemos expuesto: brevedad que no debe confundirse con ligereza; rapidez, que no tiene por qué significar irreflexión; e inteligibilidad.

Mary Luz Vallejo (1993: 37) realiza una interesante reflexión sobre lo que entiende que debe ser el estilo de la crítica: "La crítica periodística se distingue por tres rasgos: es breve, clara y remite a la actualidad". Asimismo, destaca como cualidades de la crítica periodística las moderadas licencias creativas, la coherencia de las ideas, la concentración argumental sobre las ideas esenciales y la ponderación en los juicios de valor.

No hay que olvidar nunca el medio a través del cual se publica y el público al que se dirige. Cuanto más masivo es el medio, más inteligible debe ser la crítica. Tampoco se puede obviar que el crítico asume el papel de redactor, instructor, orientador y juez.

En esta faceta profesional, un elemento esencial siempre es la eficacia. Una buena crítica debe ser fluida, debe llegar con eficacia. Manuel Seco (1979: 77-90) advierte de los peligros que pueden correr la comprensión y legibilidad de los textos si se carga las críticas de tecnicismos. También Juan Gutiérrez Palacio (1984: 233) alerta sobre la importancia del lenguaje utilizado en este género periodístico. "A fin de llegar a su público, tiene que escribir en el lenguaje que entiendan los lectores y de una manera que les agrade. Por lo mismo, no debe usar una terminología o fraseología técnica o demasiadas frases elevadas, sobre todo de naturaleza subjetiva. Si se usa una terminología técnica que resulte oscura, hay que explicarla o interpretarla para el lector".

Por eso queremos recordar aquí las palabras de este mismo autor (1984: 234) cuando afirma que el crítico escribe para personas que no conocen la obra pero que tienen intención de acercarse a ella; también para personas que sí la conocen y quieren contrastar opiniones o para los que probablemente no la lleguen a conocer pero quieren saber algo de lo cual comentar. Estas reflexiones realizadas por este autor para la crítica artística, sirven de lleno para cualquier tipo de crítica periodística.

Una crítica periodística debe satisfacer la curiosidad de los lectores que no son expertos del producto analizado, debe darles unas pautas que les acerque al conocimiento de las cosas. Pero también debe contribuir a fortalecer las opiniones de la audiencia que sí tiene un cierto grado de experiencia sobre el producto que se analiza. Por eso la crítica periodística debe apuntar ideas que ayuden a conocer las cosas y tiene que ayudar a profundizar sobre el conocimiento de las mismas. 
Por lo que respecta al tipo de razonamientos utilizados por la crítica periodística podemos decir que se suele construir a través de procedimientos deductivos (partir de una idea general y aceptada para especificar otras cualidades) o inductivos (partir de rasgos y características concretas hasta concluir en ideas generales). En cualquiera de estos dos procedimientos, suelen ser frecuentes también las analogías o comparaciones con referencias a objetos o sistemas que son conocidos por el público. En cualquier caso, es importante desprenderse de los tópicos y acudir a ese lenguaje ágil del que ya hemos hablado.

Mary Luz Vallejo (1994: 41) destaca dentro de las características que debe tener el estilo de la crítica, la necesidad de "hallar la expresión eficaz y sugestiva, considerando sobre todo que la crítica, como género creativo, invita al juego de palabras, al empleo de figuras que comuniquen nuevas significaciones, sin olvidar que tanto las estructuras como las figuras novedosas deben estar al servicio de la argumentación".

Esta misma autora (1994: 42) recoge una serie de características que, según su criterio, debe tener el lenguaje de la crítica. "Para construir y analizar el lenguaje de la crítica también hay que tener en cuenta la estructura de las frases, la selección apropiada de las palabras (sobre todo de los adjetivos y de los adverbios), las alusiones, las figuras retóricas, los términos coloquiales y otros recursos que dan cuenta de la claridad, elegancia y variedad del estilo".

Huir del lenguaje cerrado, acudir a términos concretos y no abstractos y no caer en la tentación de escribir sólo para expertos, serían algunas otras cualidades del lenguaje que se debe utilizar en la crítica periodística.

Para enmarcar el análisis de las características textuales de la crítica de vinos, consideramos que es necesario seguir el patrón marcado por Luisa Santamaría (1997: 148) que establece cuatro modelos, actualmente vigentes, sobre los que se estructuran las críticas periodísticas: el modelo estético, el formalista, el culturalista y el sociológico. Nuestro objetivo es, de acuerdo con estos cuatro patrones, buscar el lugar o espacio estético que ocupan las críticas de vinos en los medios de comunicación de masas.

El modelo estético está ligado a una visión impresionista de la obra analizada. Es la exaltación de los valores y actitudes estéticas. El crítico tiene una gran libertad para estudiar y especular sobre la obra analizada, porque él es también un creador.

El modelo formalista destaca fundamentalmente las actitudes científicas frente a las estéticas. Es, en el caso que nos ocupa a través de este trabajo, el análisis frío de las cualidades científicas y técnicas de los productos criticados frente a la estética de los mismos.

El modelo culturalista estudia el producto en relación con los condicionamientos históricos que lo han hecho posible, con el medio ambiente en que se desarrolló el producto e inspiró a su autor. 
El modelo sociológico analiza los productos desde la perspectiva de que la estética no responde a un canon inmutable o a un criterio definido de lo que debe ser la belleza; por el contrario es un resultado variable, una superestructura. Su estimación depende de valores circunstanciales.

A la hora de abordar una crítica periodística, hay que mantener un exquisito cuidado por el estilo. Mary Luz Vallejo (1993: 31) resume lo que ella considera que son los pecados capitales de la crítica periodística. Por su interés y aplicación práctica a la crítica de vinos, vamos a enumerar brevemente algunos:

1. Interés desmedido por lo nuevo, sin criterios de selección y jerarquía de valores. La búsqueda de la primicia.

2. Falta de creatividad y excesiva creatividad. Nos fijaremos en este segundo aspecto. "El crítico usa la obra como pretexto para impresionar al lector con su erudición en cuestiones que apenas rozan el objeto de análisis".

3. Superficialidad. La vertiginosa rapidez no da tregua a la crítica reflexiva.

4. Pobre soporte teórico. Adolece de falta de fundamentos teóricos debido al poco interés por la investigación, adquiriendo, generalmente, un carácter lírico e impresionista (en el sentido peyorativo del término).

5. Desconocimiento del público. La crítica pierde cada vez más su función social y orientadora porque ignora los intereses del público al que va dirigida.

6. Lenguaje críptico. A menudo emplea una jerga hueca y sofisticada que sólo llega a los iniciados, como "abstrusa ciencia abstracta" incomprensible para el lector medio. Suele denotar un atracón de lecturas mal digeridas sobre las escuelas de moda.

7. Amiguismo. Los críticos han terminado por confundirse con los partidarios o los enemigos, pero ninguno de los dos tasa o valora, sino que se vincula o se opone, infravalora o sobrevalora.

\section{Estructura de la crítica}

Cuando hablamos de las características generales de la crítica periodística, lo hacemos desde la consciencia de que estamos ante un género periodístico de opinión que es singular, y esto es así por la presencia de elementos estrictamente informativos junto a los opinativos.

Si bien los elementos esenciales que deben presidir la crítica periodística son la orientación y la educación del público, la crítica al mismo tiempo también informa. Entramos así de lleno en una de las características que hacen de este género un sistema de comunicación singular: suministra información. 
La mayoría de los autores se refiere a la crítica como género que suministra información y opinión. Martín Vivaldi (1990: 338) destaca dentro de una amplia gama de cualidades de la crítica la de ser fielmente informativa: "El lector quiere saber si aquello que se critica es bueno o malo y por qué".

También Lorenzo Gomis (1987: 37) se refiere a esta singularidad cuando afirma que "la crítica en un medio de comunicación aunque como crítica tiene la función de enjuiciar y valorar la obra, tiene también un carácter informativo, descriptivo y orientador".

La combinación de elementos informativos y opinativos hace que a la hora de redactar la crítica se haga bajo una estructura externa singular en la que la información suministrada en una ficha técnica juega un papel importante. Como punto de partida para referirnos a la estructura externa de la crítica podemos decir que no existen estructuras cerradas a la hora de organizar externamente este género periodístico. De hecho, dadas las conexiones que como hemos visto puede tener con la crónica (Núñez Ladevéze), o el reportaje, puede adoptar estructuras externas similares e incluso una redacción plagada de descripciones, interpretaciones e incluso citas directas para recoger declaraciones.

La estructura externa, al igual que el lenguaje utilizado, depende también del tipo de crítica. No se puede abordar igual una crítica literaria o artística que otra dedicada directamente a bienes para el consumo.

Sin embargo, dada la combinación de los elementos informativos y opinativos que la crítica propone, todos los autores coinciden en destacar dentro de su estructura las siguientes particularidades:

Cabeza de titulación: en la crítica es esencial la función de complementariedad que desempeñan dos elementos esenciales de la cabeza o encabezamiento: el antetítulo y el título. En ocasiones, según los medios de comunicación, el titular se complementa en vez de con un antetítulo con un subtítulo, pero en los dos casos antetítulo o subtítulo juegan un papel similar.

El titular es casi siempre breve, interpretativo u opinativo. Suele recoger en una frase breve y contundente la sentencia sobre la obra criticada. Es casi siempre apelativo: apunta el tema sobre el que informa, pero no suministra información concreta sobre él. Es similar al de cualquier otro género de opinión.

El antetítulo o subtítulo es siempre complementario del titular y funciona a modo de un titular informativo. Los elementos informativos aparecen siempre aquí, respondiendo a las preguntas qué y quién. Esta complementariedad entre estos dos elementos de la titulación es importante en la crítica. El titular es apelativo, categórico, opinativo o, en ocasiones, interpretativo. El antetítulo o el subtítulo recogen los elementos informativos relacionados con el autor o la obra criticada, sea ésta del tipo que sea.

La ficha técnica: suele recoger los elementos más informativos de la crítica y aparece diferenciada tipográficamente. Es un recurso apropiado para suministrar casi toda la información que incorpora la 
crítica. Suele aparecer habitualmente debajo del título y del subtítulo, aunque algunos medios de comunicación la colocan también al final del texto. Funciona a modo de una guía que suministra datos que son útiles para el lector. Por ejemplo, en una crítica literaria Mary Luz Vallejo (1994: 45) recomienda que aparezca en la ficha el nombre del autor, la editorial, el lugar y la fecha de publicación de la obra, el número de páginas y el precio al público.

Cuerpo: la mayoría de los autores recomiendan que el cuerpo de la crítica se organice alrededor de tres partes: una primera en la que el crítico presenta la tesis que desarrollará en el texto, una segunda en la que se analiza el producto y se exponen sus características esenciales y unos párrafos finales en los que aparecen las sentencias sobre la obra juzgada, es lo que viene a denominarse "el veredicto".

A pesar de que casi todos los autores proponen este esquema para la crítica literaria o artística, se trata de un esquema válido para cualquier tipo de crítica y, por qué no, también para la que aquí proponemos que es la crítica de vinos.

El la primera parte del cuerpo, según Natividad Abril (1999: 199) el crítico "presenta al autor y lo relaciona con la obra objeto de análisis con su producción anterior. Contextualiza el último trabajo". En este apartado, según esta misma autora, "se aconseja utilizar recursos literarios y aportar descripciones vivas, apuntes irónicos, ejemplos, esbozos de retratos, etc.; en esta primera parte, también se pueden enumerar los puntos clave que se tratarán a continuación".

En la segunda parte es donde se desarrollan todos los elementos argumentativos para la aprobación o rechazo de la obra analizada. Es donde aparecen los juicios del crítico y donde también pone sobre el papel sus recursos estilísticos en un texto que debe estar siempre impregnado de valoraciones, dado el carácter opinativo de la crítica.

“El texto de una crítica, afirman Luisa Santamaría y María Jesús Casals (2000: 340), debe ser todo lo creativo e instructivo que pueda dar de sí la imaginación y la cultura de su autor. [...] Aquí se encuentra por ejemplo la necesidad de contribuir a aumentar los conocimientos del lector echando mano de las fuentes y referencias artísticas y literarias [...]. Los procedimientos narrativos, los personajes, las creaciones de los tiempos y los espacios, el punto de vista, son cuestiones que definen una obra, el estilo de un autor, las influencias recibidas, la conexión con su tiempo, los valores artísticos que propone. Todo ello debe estar valorado por el crítico".

La tercera parte del cuerpo se destina al veredicto. Es decir, para las conclusiones que se derivan de lo expuesto en los párrafos anteriores. Es la parte esencial del texto porque una buena crítica tiene que tener unos juicios de valor contundentes. En ocasiones los críticos prefieren dejar abiertas las conclusiones para que sea el propio lector el que extraiga sus propias conclusiones. Sin embargo, por la propia esencia de la crítica, es mejor que aparezca el juicio del crítico, que al fin y al cabo es lo que espera el público. 


\section{El papel de los críticos}

Finalmente, pensamos analizar también el papel del crítico de vinos dentro de las características que pensamos que debe reunir cualquier periodista o experto que se dedica a la crítica periodística.

El crítico, tal y como afirma Gonzalo Martín Vivaldi (1990: 340) "debe ser ante todo un espectador como nosotros, con las mismas emociones y los mismos gustos". Es alguien sobre el que delegamos la toma de decisiones, por eso está obligado a elegir y decidir. Por eso, como afirma también Martín Vivaldi, "tiene que ser también un juez, pero sin olvidar que sus veredictos no tienen valor por sí mismo, sino en relación con nosotros, que es a quien él tiene que rendir cuentas".

El trabajo de crítico demanda una serie de cualidades entre las que se puede destacar: un definida afición por la rama elegida, un profundo conocimiento de los temas que se van a criticar y un punto de vista bien definido, ya que toda crítica requiere una opción personal.

Intentamos observar aquí con qué actitud aborda el crítico de vinos la obra realizada. Una crítica es un ensayo, una opinión, y ésta puede desembocar con facilidad en conclusiones autoritarias y terminantes. Pero un crítico tampoco debe de olvidar que él tampoco está por encima del bien y del mal y que, por lo tanto, su obra puede ser juzgada con el mismo derecho y utilidad social que son juzgados escritores y artistas.

Para observar este apartado consideramos oportuno referirse a una serie de características que según García Lorenzo debe reunir un crítico. Características que recogen Luisa Santamaría y María Jesús Casals (2000: 355-356) y que son las siguientes: rigor intelectual, objetividad, independencia y sinceridad en los juicios, huida del paternalismo, no utilizar la crítica elusiva ni la arbitrariedad, profesionalidad y una actitud cerrada ante el experimentalismo.

\section{1. ¿Qué hace falta para ejercer la crítica?}

Lógicamente, en primer lugar, es necesario un conocimiento profundo sobre el tema criticado, junto con buenas dosis de madurez, responsabilidad, ponderación y un conocimiento técnico profundo.

Hay autores que señalan a la honradez como característica esencial para la práctica periodística de la crítica. No vamos a desglosar un rosario de características para la práctica de ese género, ya que entendemos que todas ellas deben ser consustanciales a cualquier práctica de cualquier especialización periodística. O lo que es lo mismo, a la propia esencia y práctica del periodismo.

Martín Vivaldi, además del desinterés personal, es decir, tal y como afirma "probidad, en el sentido corriente de la expresión. Hay que ser incorruptible", destaca como exigencias la pasión por el arte que se critica (es decir, por el tema) y la competencia (1990: 341). 
Otros autores, como Luisa Santamaría, se prestan a destacar y enumerar algunas cualidades que consideran esenciales para la práctica de la crítica periodística. Así, esta autora destaca fundamentalmente tres: una definida afición por la rama elegida, un acervo de conocimientos en el campo de que se trate y un punto de vista bien definido (1997: 149).

Martín Vivaldi hace una alusión indirecta a la ponderación del crítico y para ello establece una serie de diferencias entre lo que entendemos por crítica y la censura. "Criticar no es censurar, porque la censura se fija exclusivamente en los aspectos negativos, mientras que la crítica debe hacerlo en lo positivo y lo negativo. Criticar es enjuiciar. Por eso hace falta mucha prudencia y conocer profundamente el tema" (1990: 337).

Se supone que el crítico es un conocedor experto. El conocimiento sobre el tema le da autoridad para emitir juicios sobre él confeccionando un mensaje orientador que resulte inteligible para un público amplio.

El resto de cualidades son las propias que se deben exigir a la práctica periodística: sentido crítico, formación profunda sobre el tema que critica, valores éticos, espíritu insobornable y facilidad para la escritura.

Toda esta gama de recomendaciones y otras muchas más son necesarias dada la responsabilidad adquirida por el crítico con el público al que se dirige. "Es necesario insistir en la gran responsabilidad contraída por un crítico respecto a sus lectores u oyentes. En definitiva, todos somos a la postre receptores y la labor de la crítica nos afecta y nos interesa ya que, como consumidores de cultura, estamos en manos de los críticos mucho más que de los propios creadores" (Santamaría y Casals, 2000: 315).

Entre crítico y lector debe existir un reconocimiento compartido. El crítico debe conocer el impacto que sus observaciones pueden ejercer sobre el público y éste debe acabar por reconocer las cualidades del crítico que directa o indirectamente le orienta hacia el consumo.

Por eso, para hablar del papel de los críticos es necesario referirse también a la especialización y la profesionalidad. El conocimiento en profundidad del tema que se critica es condición imprescindible para practicar la crítica periodística. La crítica informa, pero sobre todo orienta y educa. Además, todo ello, con la intención latente u oculta de potenciar el consumo. La crítica periodística busca el estímulo del lector, abrir sus ojos hacia nuevos temas, nuevos productos de consumo, sean culturales o no, nuevas fronteras.

Para ejercer la crítica hace falta especialización, es decir, un amplio bagaje de conocimientos que permita al autor del texto una visión profunda de la obra juzgada, pero realizada con sencillez, para que sea fácilmente comprendida. Esta necesaria especialización es lo que hace que en la mayoría de los medios de comunicación la crítica periodística la ejerzan especialistas, que no periodistas del medio de comunicación. 
Un especialista que quiera practicar la crítica periodística deberá conocer perfectamente las técnicas periodísticas, si lo que se pretende, como es lógico que así sea, es que la crítica llegue a públicos masivos, ya que se canaliza a través de medios de comunicación.

La especialización es necesaria porque sólo desde el conocimiento profundo de los temas que se abordan se puede llegar a juicios exactos y ponderados, que son dos características que deben estar presentes en la crítica.

\section{El lenguaje de la crítica de vinos}

La crítica vinícola hace uso de lo que podemos denominar un lenguaje técnico-científico; es decir, el uso de palabras y expresiones empleadas exclusivamente y con sentido distinto del vulgar dentro de un ámbito especializado, en este caso, el de la enología y la cata.

La crítica enológica pertenece al subgrupo de "crítica de consumo" (no se valora una creación cultural, sino un producto industrial, aunque en éste, en contados casos, se puedan encontrar ciertos aspectos artesanales; aunque en ciertos textos se observan las características propias de la crítica artística (alusión a otros campos semánticos, una rica adjetivación, etc.). En el caso de que no exista una ficha técnica lo suficientemente clara e informativa, la sublimación del lenguaje del vino no siempre redunda en la utilidad del texto para el lector, que a no ser que sea ya un experto en cuestiones enológicas corre el riesgo de no entender completamente lo que se le quiere transmitir.

Para explicar las cualidades de un vino, el periodista necesita obligatoriamente utilizar un tipo de lenguaje peculiar, con un léxico propio, especializado. Esto es así porque técnicamente es imposible abordar una crítica en la que se exponen las cualidades de un vino sin acudir a las designaciones clásicas que tradicionalmente se han utilizado para explicar las cualidades de ese producto.

Existen diversas propuestas de tasting report publicadas en castellano, como son las asumidas por los autores de diversas guías de vinos (Peñín, Proensa, Campsa, etc.). Por otro lado, tanto la Fundación Caja Rioja como el propio Consejo Regulador de la DOC Rioja (www.riojawine.com) tienen publicados sendos manuales de cata en los que se recogen la terminología básica que se debe de emplear en la descripción de la degustación de un vino. Otros autores, como Carlos Falcó, marqués de Griñón, en su célebre Entender de vino, también recogen un completo glosario de la terminología utilizada en la cata. Fernando García del Río incluso propone en su obra El método del catador una sistematización rigurosa en la descripción de los diversos aspectos organolépticos relacionados con el vino.

Sin embargo, algunos críticos, a la hora de elaborar sus textos, en ocasiones echan mano del léxico general, común a todos los hablantes, para explicar esas cualidades a las que nos estamos refiriendo. Con ello, no hacen otra cosa que dotar al léxico general, reconocido y admitido, de significados distintos. 
Cuando el crítico hace esto ignora que el vocabulario científico y técnico está sujeto a las normas sintácticas generales. La exposición de un tema científico se lleva a cabo del mismo modo que cualquier otra forma de expresión, y su carácter científico se manifiesta en la presencia de términos especializados; sin estos vocablos especializados un texto científico no quedaría caracterizado como tal.

Al contrario de lo que sucede con un lenguaje general, sea coloquial o más elevado, el lenguaje especializado, científico o técnico, como prefiramos llamarlo, se caracteriza porque busca describir con total precisión un determinado campo. Es decir, estamos ante un lenguaje unívoco.

Definir con precisión no es otra cosa que utilizar un único término para explicar un concepto. Cuando utilizamos varios términos para definir el mismo concepto no hacemos más que añadir dificultad, restar precisión y exactitud a lo que definimos.

En los lenguajes técnicos no deben existir sinónimos de igual significación. Cuando se quiere explicar una característica de un producto a través de un lenguaje técnico utilizamos un léxico tan preciso que no debe ni puede existir otra palabra que sirva para designar lo mismo. Si existe otra palabra, si utilizamos un sinónimo para describir lo mismo, lo único que hacemos es erosionar la eficacia del lenguaje técnico.

La existencia de sinónimos para definir las cosas es inversamente proporcional a la exactitud y la precisión del lenguaje técnico y su uso no hace sino coloquizar un lenguaje que en principio se creó para delimitar nítidamente un campo concreto de la realidad.

El vocabulario propio de la viticultura utiliza a menudo palabras del léxico general (tierno, vigoroso, sofisticado, etc.), lo que puede inducir al lector no especializado a extraer un sentido que nada tiene que ver con la caracterización que se pretende hacer cuando se utiliza un léxico especializado.

Así, por poner un ejemplo, "tierno" como término de uso general viene a significar, según el diccionario de la Real Academia de la Lengua, "afectuoso, cariñoso y amable", pero dentro del vocabulario técnico de la cata "se dice del vino poco ácido, ligero y con poco extracto".

Cuando utilizamos un lenguaje especializado los vocablos son insustituibles y no pueden ser suplantados por otros que actúen como sinónimos o semejantes porque éstos no pueden existir. Por eso es imprescindible homogeneizar el uso de ese lenguaje.

Cuando el lector de prensa acude a una crítica de vinos es consciente y sabe por experiencia que se va a encontrar con unos términos especializados claramente reconocidos para describir las cualidades de un producto. Existen unos términos precisos cuyo uso implica una normalización en el uso de ese lenguaje. Para Fernando García del Río (2004: 13) esa normalización "es el resultado de un efecto mimético en el lenguaje que ha ido sedimentando durante años dando lugar más a una jerga que a un vocabulario científico". 
Cuando el crítico de vinos analiza un producto y confecciona un texto con un vocabulario en el que predominan los términos adoptados de la lengua general, lo único que consigue es que el lector no especializado confunda su significado genérico con el significado técnico, haciendo una interpretación aberrante del mismo.

“Tratar de leer un texto especializado científico o técnico sin ser especialista en el campo correspondiente es casi lo mismo que tratar de leer un texto literario en una lengua que no se conoce. Es posible que el lector no sienta como ajenas a su lengua las palabras que va encontrando pero finalmente tiene que convencerse de que no está entendiendo nada de nada. En un texto especializado el lector no especialista no encuentra ningún auxilio en la relación gramatical, sino que más bien sucede todo lo contrario" (Gómez Font, 2005).

En la crítica vinícola el crítico se encuentra ante el reto de transmitir unos conocimientos especializados a un público claramente heterogéneo. El empleo de un vocabulario técnico no debería ser obstáculo para la inteligibilidad de los contenidos, dado que otras críticas especializadas en coches, ópera o moda, también exigen a su lector unos conocimientos medios que el aficionado no tarda en hacer suyos.

Si tenemos en cuenta que el ámbito de publicación de estas críticas no es el de las revistas técnicas, sino la prensa de divulgación general, sería suficiente con recurrir a un vocabulario técnico homogéneo y no excesivamente extenso para poder transmitir esos conocimientos de forma rigurosa y unívoca.

Una de las dificultades mayores con las que se puede encontrar un crítico de vinos es la utilización de un lenguaje que sea inteligible para el público al que se dirige. Sin embargo, en la práctica, lo normal y frecuente es que los críticos utilicen un lenguaje oscuro y sombrío, que no está justificado a pesar de las dificultades que tiene una crítica periodística, como es la de vinos, que debe acudir a múltiples tecnicismos para explicar las cualidades del producto que estudia.

Es tan grande la tendencia de algunos autores a acudir a expresiones ininteligibles que puede aparecer siempre la duda de que el autor lo haga así porque es consciente de que utiliza un mecanismo para ocultar unas críticas carentes de contenido, una proliferación de adjetivaciones disparatadas, tópicos y despliegue de toda una gama de figuras retóricas para construir un texto que no sea fácilmente entendido por la gente.

El punto de partida para hablar del lenguaje de la crítica de vinos debe ser claro: si se hace en revistas especializadas el lenguaje podrá ser más técnico. Si se escribe para medios de comunicación masivos deberá trabajarse con un lenguaje al alcance de cualquier persona de cultura media, sea o no experto en el tema.

Que el lenguaje del vino está plagado de tecnicismos no hay ninguna duda. Que además es prácticamente imposible eludirlos, tampoco. Lo que también es cierto es que el lenguaje técnico de la crítica 
de vinos no es más complejo que cualquier otro lenguaje relacionado, por ejemplo, con la crítica de coches o de ordenadores. Lo que sucede, es que en estos dos casos se busca un lenguaje que sea comprendido por todos para que el producto pueda ser consumido. En el caso de la crítica de vinos se ha llegado al ridículo de buscar que la crítica sea ininteligible, porque esa dificultad, al parecer, ha sido considerada como sinónimo de calidad.

Una crítica de vinos ininteligible es una mala crítica. Porque no cumple con los requisitos básicos de los géneros que buscan el convencimiento del lector. La crítica de vinos se hace para convencer y para convencer debe ser primero comprendida. Una crítica que no convence no puede ser nunca una buena crítica.

Es cierto que la crítica de vinos no puede eludir los tecnicismos, algunos de ellos, además, con grandes dificultades para la concreción. Así, para referirse al color, es imposible eludir hablar de si un vino es "vivo" o "cubierto" o "pálido" o "turbio". Lo que no es imposible, sino más bien recomendable, es huir de los términos (normalmente adjetivaciones disparatadas) que no ayudan a definir cualidades, sino más bien a diluirlas. Lo que tampoco es imposible y sí recomendable es acompañar los tecnicismos con explicaciones inteligibles para el público. Así, en los ejemplos anteriores, podemos decir que un vino es "vivo", es decir, "de color brillante"; o que está "cubierto", es decir, "de color profundo y oscuro"; que es de color "pálido", es decir, con "poco color o con falta de color que, normalmente, denota falta de concentración"; o que está "turbio", es decir, que está "sucio, revuelto o falto de transparencia debido a la presencia de partículas en suspensión u otros defectos de elaboración”.

Decimos que no sólo es recomendable sino de gran importancia porque al tiempo que dotamos a cada tecnicismo de multitud de matices ayudamos al lector a adquirir conocimientos sobre el tema, una de las características que también deben reunir las críticas de consumo.

La dificultad de comprensión del lenguaje en la crítica de vinos viene cuando a los numerosos tecnicismos añadimos adjetivaciones exageradas o utilizamos expresiones no reconocidas o aceptadas como expresiones técnicas para designar cualidades del producto.

Muchas de estas adjetivaciones exageradas y las permanentes referencias que hacen los críticos de vinos a campos semánticos como la belleza o la sensualidad se hacen como consecuencia de las propias adjetivaciones que algunos enólogos utilizan cuando hablan del vino. Así, para la enóloga española María Isabel Mijares, en unas declaraciones al diario chileno El Mercurio (publicadas el 16/05/2002) señalaba lo siguiente: "El vino tiene forma, tiene cuerpo, tiene volumen, tiene brazos, tiene alma. Por eso hay vinos que abrazan, hay vinos mimosos, hay vinos nostálgicos. Yo tengo la gran suerte de poder dialogar con el vino. Cuando tengo una copa enfrente, parece como si te estuviera contando un poco toda su vida".

No hay que olvidar, además, que cuando se utilizan símiles en la crítica de vinos difundida en medios de comunicación masivos, éstos deben ser entendidos por casi todo el público, o por amplios 
sectores del mismo. No es correcto utilizar un lenguaje totalmente técnico y casi ininteligible en medios de comunicación masivos. Cuanto más especializado sea el medio más técnico podrá ser el lenguaje utilizado.

Entre el desmesurado tecnicismo y la adjetivación escandalosa hay un amplio terreno en el que se puede mover el lenguaje de la crítica de vinos. Así por ejemplo, para describir los aromas o sabores de un vino, decir que es "frutal" no es decir nada si no se explica a qué tipo de aromas o sabores frutales se refiere: manzana, pera, melocotón, naranja, frutos silvestres o del bosque (mora, arándano, cassis, etc.).

Miguel Brascó, escritor, músico y crítico gastronómico, se ha reído en varias ocasiones de los críticos que dicen de un vino que tiene aromas especialmente extraños. Según Brascó, para definir las cualidades de un vino "se dicen auténticas barbaridades. Hay un vocabulario inventado para describir los aromas y los sabores. Es una jerga de enólogos que es escuchada por algún bobeta a quien le parece sofisticado hablar como ellos y empieza a imitarles el discurso. Si te digo que un vino tiene aroma a frutas tropicales, en realidad no digo nada. ¿Qué quiero decir con frutas tropicales? ¿Cuáles son? O si digo que el vino blanco tiene aroma a flores blancas, ¿̇a cuál?, porque las rosas, las gardenias, los jazmines, las margaritas, todas tienen sus propios aromas. También me río mucho cuando alguien dice que el vino tiene aroma a trufas que, por otro lado, acá no se consiguen. Y el tema es que las trufas tienen olor a pedo. Y como no lo saben, lo usan porque tiene glamour literario" (http://www.3puntos.com/).

También Cristino Álvarez (Caius Apicius), colaborador de revistas como Sobremesa y de periódicos como La Voz de Galicia y crítico gastronómico desde hace ya varias décadas, opina sobre las adjetivaciones sin sentido que se utilizan en las críticas de vinos. Así, se refiere a algunas valoraciones que se hacen en la actualidad y que diferencian entre vinos masculinos y femeninos: "Mira, de entrada no entiendo ese tipo de valoración acerca de un vino. $\mathrm{Y}$ ya sé que se emplea a veces y que son términos aceptados mayoritariamente. Pero, ¿a qué se refieren? ¿A un tipo de vino con características que habitualmente se atribuyen a la mujer como la dulzura, la amabilidad, la elegancia, el refinamiento? Pues me parece muy machista, porque por el contrario ¿a qué estamos llamando un vino masculino? iA uno más bruto, más áspero, o más qué? No me gusta nada esa calificación, porque aunque a veces comentes de forma coloquial «éste es un vino con toda la barba», en cuestión de vinos creo que no se puede hablar de géneros, sólo de vino bueno y vino malo" (http://www.accua.com/gastro/conten/ GAS1133.asp).

En el caso concreto de la prensa española, cabe afirmar que la crítica enológica como género (o subgénero de la crítica de consumo) no está aún suficientemente desarrollada. En la mayor parte de los diarios este tipo de textos queda relegado a los suplementos temáticos del fin de semana. Es lo que sucede con las críticas de Carlos Delgado para el suplemento El Viajero de El País; con las de José Luís Recio para El Semanal del grupo Vocento (también distribuido por publicaciones como Heraldo de Ara- 
gón, La Voz de Galicia, Diario de Mallorca y otras cabeceras regionales); con las de Alfred Rexach para el Magazine de La Vanguardia, La Razón y el grupo Prensa Ibérica; o con las de Quim Vila para el Dominical del grupo Zeta y diarios locales de Prisa.

La mayor parte de estos textos se encuentran más cercanos a la reseña valorativa que a una crítica propiamente dicha, que cuente con un titular expresivo o apelativo, una ficha técnica y una estructura textual en la que se argumente, de una manera útil para el lector, la calidad o defectos de un determinado producto.

Especialmente preocupante es la ausencia de una clara ficha técnica en algunas críticas, lo que hace que se omitan elementos importantes en la crítica periodística. A fin de cuentas, los datos informativos son necesarios para identificar el producto y sus características técnicas.

Por otro lado, el empleo de una serie de tecnicismos al alcance de una minoría y la utilización de una adjetivación ambigua, que en nada contribuye a aclarar los conceptos, hace que los textos sobre vinos parezcan dirigidos no a una audiencia heterogénea, sino a un público selecto e iniciado en el mundo de la cata. Por lo tanto, en estos textos no se cumpliría el supuesto objetivo de asesorar, o en su caso educar, a un lector medio que no tiene porqué ser experto en la materia.

Se da la circunstancia de que cuando el crítico se limita en sus textos a explicar las características de un vino con los tecnicismos reconocidos, el texto carece de explicaciones pero gana en concreción e inteligibilidad. La vinculación de tecnicismos a adjetivaciones exageradas dificulta la comprensión del texto y difumina el sentido de la crítica. Sin embargo, en los textos escuetos y precisos, con tecnicismos reconocidos, no se ayuda al lector a comprender con precisión las cualidades que se le plantean. Esto es así porque no aparecen explicaciones sobre los tecnicismos empleados. Quizá sería oportuno, para que estos textos logren una mayor eficacia divulgativa, no sólo enunciar las cualidades del vino, sino también explicarlas someramente.

En cualquier caso y a pesar del poder que en el ámbito internacional se otorga a críticos como Robert Parker como creadores de opinión en el mundo vinícola, el reputado enólogo Manuel Ruiz Hernández alude al propio poder adquisitivo de las audiencias como factor que explica las tendencias en el consumo del vino: "La historia de la calidad de los vinos se estima que es una orientación desde las zonas de origen. No es así. La calidad la marca el polo comprador en base a su poder adquisitivo. En un principio fue Roma que estableció para su interés el mapa de calidades en su imperio. Después fueron las Hansas de Londres, Rotterdam, Brujas y Hamburgo quienes determinaron zonas de su interés. Y actualmente, en importante medida, son los Estados Unidos" (http://www.arrakis.es/mruizh).

\section{Referencias bibliográficas}

- Abril Vargas, Natividad (1999): Periodismo de opinión. Síntesis, Madrid.

- Aguilera, O. (1993): "La crítica, control de qualitat dels productes culturals. Composició dels textos periodístics”, Periodística, n. ${ }^{\circ}$ 6, pp. 101-109. 
- Andre, Víctor (2003): Aprensa a conocer los vinos. Ediciones Robinbook, Barcelona.

- Aristóteles (1990): Retórica. Gredos, Madrid.

- Armañanzas, Emy y Díaz Noci, Javier (1996): Géneros de opinión. Universidad del País Vasco.

- Armentia, Alberdi, Caminos y Marín (2002): El diario de servicios en España. Septem, Oviedo.

- Armentia Vizuete, J. I. y Caminos Marcet, José (2003): Fundamentos de periodismo impreso. Ariel, Barcelona.

- Azorín (1947): “La evolución de la crítica”, en Obras Completas. Aguilar, Madrid: 1989.

- Berrio, Jordi (1983): Teoría de la persuasión. Mitre, Barcelona.

- Bradbury, Malcom y Palmer, David (1974): Crítica contemporánea. Cátedra, Madrid.

- Brown, J. A. C. (1986): Técnicas de persuasión. Alianza, Madrid.

- Campsa (2003): Los mejores vinos de España. Repsol YPF, Madrid.

- Cantavella, Juan y Serrano, José Francisco (coords.) (2004): Redacción para periodistas: informar e interpretar. Ariel, Barcelona.

- Casado, Manuel y Vilarnovo, Antonio (1989b): “Lingüística del texto y textos periodísticos” en Periodística, n.. ${ }^{\circ} 1$, Barcelona.

- Casado, Manuel y Vilarnovo, Antonio (1992): Discurso, tipos de texto y comunicación. EUNSA, Pamplona.

- Casasús, Josep María (1988): Introducción a la periodística. Teide, Barcelona.

- Casasús, Josep Maria y Núñez Ladevéze, Luis (1991): Estilo y géneros periodísticos. Ariel, Barcelona.

- Chillón, Luis Albert (1993): Literatura y periodisme. Universidad de Alicante, Alicante.

- Dario, Rubén (1963): “La crítica”, en Obras Completas, vol.3 pp. 325-331. Aguilar, Madrid.

- Dijk, Teun A. van (1983): La ciencia del texto. Paidós Comunicación, Barcelona.

- Dijk, Teun A. van (1984): Texto y contexto (Semántica y Pragmática del discurso). Cátedra, Madrid.

- Dijk, Teun A. van (1990): La noticia como discurso. Comprensión, estructura y producción de la información. Paidós Comunicación, Barcelona.

- Dovifat, Emil (1960): Periodismo. Uteha, México.

- Eco, Umberto (1998): Los límites de la interpretación. Lumen, Barcelona. 
- Eliot, Thomas S. (1995): Función de la poesía y función de la crítica. Seix Barral, Barcelona.

- Falcó, Carlos (2004): Entender de vino. MR ediciones, Madrid.

- Fernández Beaumont, José (1987): El lenguaje del periodismo moderno. Sociedad Española de Librería, S. A., Madrid.

- García del Río, Fernando (2004): El método del catador. Guía práctica para entender el vino. Alianza Editorial, Madrid.

- García Noblejas, José y Sánchez Aranda, Juán J. (eds.) (1990): Información y persuasión. Eunsa, Pamplona.

- Garrido Gallardo, Miguel Ángel (1982): Estudios de semiótica literaria. Tendencias de la crítica en la actualidad vistas desde España. Consejo Superior de Investigaciones Científicas, Madrid.

- Gómez Font, Alberto (2005): Conferencia en el II Coloquio “Lenguaje y Comunicación” celebrado en Caracas. http://www.elcastellano.org/alberto.html).

- Gomis, Lorenzo (1989): Teoria dels gèneres periodistics. Centre d’Investigació de la Comunicació. Barcelona.

- Gomis, Lorenzo (1991): Teoría del periodismo. Cómo se forma el presente. Paidós Comunicación, Barcelona.

- González Reyna, Susana (1991): Periodismo de opinión y discurso. Trillas, México.

- González Ruiz, Nicolás (1934): Antología de Literatura Periodística Española. Escuela de Periodismo "El Debate", Madrid.

- González Ruiz, Nicolás (1953): "La crítica”, en Periodismo, teoría y práctica (pp. 417-430). Noguer, Madrid.

- Grupo Alfa (1987): Retórica general. Paidós Comunicación, Barcelona.

- Gutiérrez Palacio, Juan (1984): Periodismo de opinión. Paraninfo, Madrid.

- Imbert, Gérard (1986): “Tipología de los textos de opinión (La subjetividad en el texto periodístico)”, en Gérard Imbert y José Vidal Beneyto (coords.), El País o la referencia dominante, pp. 155-176. Madrid.

- Lázaro Carreter, Fernando (1977): Lenguaje en periodismo escrito. Fundación Juan March, Madrid.

- Lewis, C. S. (1982): Crítica literaria: Un experimento. Bosch, Barcelona.

- Martín Vivaldi, Gonzalo (1986): Géneros periodísticos. Paraninfo, Madrid. 
- Martín Vivaldi, Gonzalo (1990): Curso de Redacción. Teoría y práctica de la composición y del estilo. Paraninfo, Madrid.

- Martínez Albertos, José Luis (1974): Redacción Periodística. Los estilos y los géneros en la prensa escrita. ATE, Madrid.

- Martínez Albertos, José Luis (1989): El lenguaje periodístico. Paraninfo, Madrid.

- Martínez Albertos, José Luis (1992): Curso general de Redacción Periodística. Paraninfo, Madrid.

- Morán Torres (1988): Géneros del periodismo de opinión. Crítica, comentario, columna, editorial. Eunsa, Pamplona.

- Muñoz, J. J. (1992): Redacción periodística. Teoría y práctica. Librería Cervantes, Salamanca.

- Núñez Ladevéze, Luis (1995): Introducción al periodismo escrito. Ariel, Barcelona.

- Núñez Ladevéze, Luis (1991): Manual para Periodismo. Ariel, Barcelona.

- Ortega y Gasset, José (1985): El espíritu de la letra. Cátedra, Madrid.

- Peñín, José (2003): Guía Peñín de los vinos de España. Pi \& Erre Ediciones, Madrid.

- Pérez Galdós, Benito (1971): Ensayos de crítica literaria. Península, Barcelona.

- Perelman, C. y Olbrechts-Tyteca, L. (1989): Tratado de argumentación. La nueva retórica. Gredos, Madrid.

- Posada, José (2001): Metafísica del vino. La hermandad de los vinos gallegos, Ourense.

- Proensa, Andrés (2003): Guía Proensa de los mejores vinos de España. Proensa, Madrid.

- Reardon, K. (1983): La persuasión en la comunicación. Paidós, Barcelona.

- Ruiz Hernández, Manuel (2004). Tratado de vinificación en tinto. AMV ediciones, Madrid.

- Ruiz Hernández, Manuel (2000). "Curso de enología para aficionados”, en www.arrakis.es/mruizh

- Santamaría Suárez, Luisa (1997): Géneros para la persuasión en periodismo. Fragua, Madrid.

- Santamaría Suárez, Luisa y Casals Carro, María Jesús (2000). La opinión periodística: Argumentos y géneros para la persuasión. Fragua, Madrid.

- Simon, Joanna (2004): Conocer el vino. Naturart, Barcelona.

- Vallejo Mejía, Mary Luz (1993): La crítica literaria como género periodístico. Eunsa, Pamplona.

- Weston, A. (1998): Las claves de la argumentación. Ariel, Barcelona. 
- Wilde, Oscar (1943): El crítico artista (Diálogos), Obras Completas. Aguilar, Madrid.

- VV. AA. (2001): El vino de Rioja. Fundación Caja Rioja, Logroño.

Revistas especializadas en crítica de vinos y en enología

Decanter

La semana vitivinícola

Revista Envero

Sobremesa. Revista de vinos y gastronomía del mundo latino.

The Wine Advocate

The Wine Spectator

Vinos y restaurantes.

Vino + gastronomía. Revista gastronómica de actualidad.

Vivir el vino 
